\title{
Iron and immunity
}

\section{By J. H. Brock and Tryfonia Mainou-Fowler", University Department of Bacteriology and Immunology, Western Infirmary, Glasgow G I $6 N T$}

There are many ways in which iron can affect immune responsiveness and resistance to infection. On the one hand, metabolic events associated with the mounting of a specific immune response may require $\mathrm{Fe}$, while at the same time invading micro-organisms may utilize Fe within the host's body for their own multiplication. Moreover, the limited solubility and potentially toxic nature of ionic Fe means that an excess of this element, or an abnormal distribution, may also predispose to disease. It is therefore not surprising to find that both Fe deficiency and $\mathrm{Fe}$ overload may be associated with increased susceptibility to infectious disease and impaired immune mechanisms. However, while Fe deficiency may very frequently have a nutritional cause it is extremely unusual for severe Fe overload to be induced by purely dietary means, it being much more commonly associated with inherited disorders of $\mathrm{Fe}$ metabolism such as haemochromatosis, or the excessive blood transfusions required in diseases such as thalassaemia. This review will therefore concentrate mainly on the effects of $\mathrm{Fe}$ deficiency on immunity.

\section{Fe and microbial growth}

The ability of proteins of the transferrin class (serum transferrin, lactoferrin and ovotransferrin) to inhibit microbial growth by sequestering $\mathrm{Fe}$ has been known for over 40 years, and has been the subject of much experimental work. This has been extensively reviewed elsewhere (Finkelstein et al. 1983; Weinberg, 1984), and hence only the in vitro significance of this activity and its possible perturbation by nutritional means will be discussed here.

It has been shown that many species of bacteria multiply more rapidly in serum if sufficient $\mathrm{Fe}$ is added to saturate the transferrin present, and animals can be made more susceptible to certain bacterial infections if the challenge dose is administered together with sufficient parenteral $\mathrm{Fe}$ to saturate serum transferrin (Weinberg, 1984). However, it is very doubtful if saturation of transferrin can ever be achieved by oral administration of $\mathrm{Fe}$, and in those cases where $\mathrm{Fe}$ overload is sufficiently severe to approach this situation it is probable that other factors such as tissue damage and dysfunction of cells of the immune system would already have caused increased susceptibility to infection. Conversely, in man the normal level of saturation of serum transferrin (about $30 \%$ ) is quite low enough to prevent

\footnotetext{
-Present address: Department of Bacteriology, University of Aberdeen, Foresterhill, Aberdeen $\mathrm{AB} 9$ 2ZD.
} 
rapid multiplication of Fe-requiring micro-organisms, and any further reduction resulting from $\mathrm{Fe}$ deficiency is unlikely to produce a significant enhancement in antimicrobial activity. In experimental animals such as mice, in which serum transferrin saturation is normally as high as $70-85 \%$ (Elin \& Wolff, 1974; Mainou-Fowler \& Brock, 1985 ), it is, however, possible that moderate Fe deficiency can actually enhance resistance to infection (Puschmann \& Ganzoni, 1977). It has also been reported that Fe-deficient mice were more resistant to experimental infection with Trypanosoma cruzi than normal controls (Lalonde \& Holbein, I984), but it is not known by what mechanism trypanosomes acquire Fe. It has been suggested that the reduction in serum transferrin saturation associated with inflammatory and infectious disease (the so-called hypoferraemia of inflammation) may also serve to enhance the effectiveness of the transferrinmediated antimicrobial system (Weinberg, 1984). Reduced susceptibility to experimental Candida infection following induction of hypoferraemia by endotoxin (Elin \& Wolff, 1974) has been reported, but again this study was conducted with mice.

In situations where $\mathrm{Fe}$ is not readily available, bacteria normally acquire this metal by synthesizing high-affinity, low-molecular-weight $\mathrm{Fe}$ chelators (siderophores; Neilands, 198I). Although many of these are capable of removing $\mathrm{Fe}$ from host Fe-binding proteins, including transferrin, it does not necessarily follow that transferrin-bound $\mathrm{Fe}$ is the most accessible to siderophores in vivo. Virtually the only studies in this area have been conducted using the siderophore desferrioxamine, which is used clinically to relieve Fe overload. Desferrioxamine can remove $\mathrm{Fe}$ from transferrin in vitro only very slowly unless other chelators with more ready access to the transferrin Fe-binding site are present (Pollack et al. 1977) and, although this siderophore can acquire sufficient Fe from transferrin in serum to enhance microbial growth, in vitro the rate of acquisition of $\mathrm{Fe}$ is very slow (Brock \& $\mathrm{Ng}, 1983$ ). It is well recognized that desferrioxamine preferentially chelates intracellular $\mathrm{Fe}$ in vitro (Hoffbrand, 1980), perhaps from the so-called labile pool (Jacobs, 1977), and consequently reduced availability of intracellular $\mathrm{Fe}$ may be more important than the lower transferrin saturation in impeding microbial acquisition of $\mathrm{Fe}$ during inflammation, if indeed this is an important function of the hypoferraemic response. It may therefore be concluded that while the Fe-binding properties of transferrin constitute an important part of non-specific immunity, it seems unlikely that the efficacy of this system can be greatly affected either by nutritional factors or inflammation. However, one allied mechanism which may be affected by dietary $\mathrm{Fe}$ is the potential ability of lactoferrin in maternal milk to prevent growth of Fe-requiring organisms such as coliforms in the neonatal gut. Again, there are numerous studies testifying to the in vitro bacteriostatic properties of lactoferrin (e.g. Reiter et al. 1975; Bishop et al. 1976; Mickelsen et al. 1982; Brock et al. 1983), but there are some in vivo studies which also suggest that orally administered Fe favours a coliform flora in the gut of the newborn. Bullen et al. (1972) showed that the numbers of Escherichia coli in the gut of newborn sucking guinea-pigs increased if the animals were dosed with 
haematin. Although haematin may exert this effect by a mechanism other than by saturating the lactoferrin in guinea-pig millk (Brock, 1980), a reduction in coliforms was also observed when ovotransferrin was added to an artificial milk given to young guinea-pigs (Antonini et al. 1977). Clinical studies have yielded conflicting results. Corda et al. ( 1983 ) were able to improve the rate of recovery from infantile gastroenteritis by feeding ovotransferrin, but Moreau et al. (1983) found that addition of bovine lactoferrin to a formula milk did not significantly change the number of coliforms in the faeces of bottle-fed babies. Further clinical studies in this area would be worthwhile to help resolve the question of whether $\mathrm{Fe}$ supplementation is harmful or beneficial to the newborn infant.

\section{Fe status and the specific immune response}

A specific immune response of any kind involves a complex series of events which include cellular activation and proliferation, and protein synthesis. Such events clearly presuppose an increase in the metabolic activity of certain cells and it is well known that major nutritional deficiencies such as protein-energy malnutrition can markedly affect cellular activity and proliferation. However, because $\mathrm{Fe}$ is required mainly for haemoglobin synthesis, it is not obvious that $\mathrm{Fe}$ deficiency may affect the function of non-erythroid cells, such as those involved in immune reactions. Nevertheless, there is evidence of impaired immune responses associated with $\mathrm{Fe}$ deficiency, and in this section the effects of Fe deficiency on the various arms of the immune response will be discussed, together with our somewhat limited knowledge of the underlying mechanisms.

\section{Clinical and experimental studies}

Antibody production. The evidence for impaired antibody production due to $\mathrm{Fe}$ deficiency is somewhat scanty. Several clinical studies have reported that serum and secretory immunoglobulin levels, and responses to immunization are normal in Fe deficiency (Chandra, 1975; MacDougall et al. 1975; Bagchi et al. 1980; Van Heerden et al. 1981; Krantman et al. 1982) even when other immune mechanisms such as cell-mediated immunity or neutrophil function are impaired. However, MacDougall \& Jacobs (1978) did report that a small sample of Fe-deficient children failed to respond to diphtheria immunization, although pre-existing immunity was not impaired. In animal models, Nalder et al. (1972) reported that the response of rats to tetanus toxoid decreased in relation to the Fe content of the diet, and Kuvibidila et al. (1982) found a decreased number of plaque-forming cells in the spleens of Fe-deficient, anaemic mice immunized with sheep erythrocytes.

Clearly, clinical studies suffer from the difficulty of rigorously excluding additional nutritional deficiencies, infections, or other factors that may affect antibody levels. The paucity of supporting information from animal studies where such variables are much easier to control (and wholly negative results less likely to be reported) may be significant. Furthermore, no attempt has been made to 
investigate mechanisms by which $\mathrm{Fe}$ might be involved in antibody production. Under these circumstances it must be concluded that evidence for an impairment of antibody production in Fe deficiency is rather unconvincing.

Cell-mediated immunity. The evidence for impaired cell-mediated immune responses resulting from $\mathrm{Fe}$ deficiency is rather stronger than that for an effect on antibody production. Reductions in delayed-type hypersensitivity skin responses in Fe deficiency have been reported in a number of studies (Joynson et al. 1972; Jacobs \& Joynson, 1974; Chandra, 1975; MacDougall et al. 1975; Krantman et al. I982), the defect often being corrected after Fe therapy. Reduced in vitro proliferative responses to mitogens have also been reported (Joynson et al. 1972; Fletcher et al. 1975; MacDougall et al. 1975; Sawitsky et al. 1976) although in some studies no difference was observed between Fe-deficient subjects and Fe-replete controls (Kulapongs et al. 1974; Gross et al. 1975; Gupta et al. I982; Krantman et al. I982). Apart from the difficulties associated with adequate control of other factors in clinical studies, the conditions under which the lymphocytes are cultured may be important, as discussed later. Studies with animal models have also shown decreased skin responses (Kuvibidila et al. 1981) and lymphocyte responses to mitogens (Soyano et al. 1982; Kuvibidila et al. 1983b,c;) which returned to normal after $\mathrm{Fe}$ repletion. Certain infections in which cell-mediated immunity is thought to play an important protective role may be associated with Fe deficiency, such as chronic mucocutaneous candidiasis (Higgs \& Wells, 1972; Fletcher et al. 1975) and experimental infection with Nippostrongylus brasiliensis (Duncombe et al. 1979). However, susceptibility to infections with other gastrointestinal parasites such as Giardia muris in the mouse (Duncombe et al. 1980) or Trichomonas in children (Greenberg \& Cline, 1979) was not affected and it is worth noting that there is little evidence of an association between increased susceptibility to tuberculosis and Fe deficiency.

Thus there appears to be better evidence for impairment of cell-mediated immunity in $\mathrm{Fe}$ deficiency than for impaired antibody responses, although there are still some conflicting results.

Phagocytic and cytolytic defences. There is some evidence that neutrophil function may be impaired in Fe deficiency. Decreased bactericidal activity and reduction of nitro-blue tetrazolium (NBT) have been reported (Chandra, 1975; MacDougall et al. 1975; Srikantia et al. 1976; Celada et al. 1979; Prasad, 1979; Yetgin et al. 1979) and Baggs \& Miller (1973, 1974) found that reduced resistance to experimental Salmonella typhimurium infection in Fe-deficient rats correlated with lower numbers of phagocytic cells in the mucosal tissue. However, there have been reports of normal neutrophil function in Fe-deficient subjects (Kulapongs et al. 1974; Van Heerden et al. 1981). There is very little information on the effect of $\mathrm{Fe}$ deficiency on macrophage function although Kuvibidila et al. (1983a) reported that the cytolytic activity of spleen and peritoneal cells from Fe-deficient mice against allogeneic tumour cells was reduced. Thus there may be some impairment of in vitro phagocytic activity in Fe deficiency, but a correlation with increased susceptibility to bacterial infection still remains to be established, and 
more information is required before the effect of $\mathrm{Fe}$ deficiency on macrophage function can be assessed.

\section{Mechanisms of impairment of immune function in Fe deficiency}

From the previous section it can be seen that despite a certain amount of conflicting evidence, certain parts of the immune response, and in particular cell-mediated immunity, may be impaired in Fe deficiency. To some extent the controversial nature of these findings could be resolved as more becomes known about the involvement of $\mathrm{Fe}$ in cellular and molecular events in immune mechanisms. There are three broad categories into which such mechanisms can be divided. First, $\mathrm{Fe}$ deficiency may give rise to intrinsic defects in cells such as lymphocytes or macrophages involved in immunological priming, with the result that they can no longer function normally in response to foreign antigens. Second, cells may be normal in function, but reduced in number. Third, cells may be normal in both number and in function, but Fe deficiency impairs the ability of these normal cells to respond to antigenic challenge. It is difficult to make such investigations in clinical studies, and consequently investigations using experimental models have proved more useful in this area. There is some evidence for all three types of mechanism.

Lymphocyte function. Evidence for intrinsic defects in lymphocytes associated with $\mathrm{Fe}$ deficiency comes from electron-microscopic studies in which degenerative changes in mitochondria have been found (Jarvis \& Jacobs, 1972; Jimenez et al. I982), the latter group noting a correlation between the degree of abnormality and the severity of $\mathrm{Fe}$ deficiency. These findings suggest that $\mathrm{Fe}$ deficiency could affect protein synthesis by lymphocytes, but evidence for this is not very convincing, as described later. The mechanism by which $\mathrm{Fe}$ deficiency causes mitochondrial abnormalities is unknown.

Reports of reduced numbers of lymphocytes, or alterations in the relative proportion of subpopulations, have to be considered along with the possibility of abnormal distribution of these cells within the body. Some clinical studies have reported that Fe-deficient or anaemic children had reduced numbers of circulating T-cells (Srikantia et al. 1976; Bagchi et al. 1980) even though B-cell numbers were normal (Bagchi et al. 1980). However, normal T-cell levels were reported in other studies (Van Heerden et al. 1981; Krantman et al. 1982). Information from experimental studies are also conflicting. Rothenbacher \& Sherman (1980) reported fewer T-cells in the thymus, and fewer B- and T-cells in the spleens of Fe-deficient sucking rats. Soyano et al. (1982) found that in Fe-deficient rats the response to mitogens was decreased in thymus cells but increased in spleen cells, a result which suggests that the distribution of lymphocytes in the different organs may have been altered. However, studies in the authors' laboratory (Mainou-Fowler \& Brock, 1985) have shown that in Fe-deficient (but not anaemic) mice the proportion of $\mathrm{T}^{-}$-cells and of the $\mathrm{LyI}^{+}$and $\mathrm{Lyz}^{+}$subsets in lymph nodes. were the same as in Fe-replete animals. Although differing degrees of Fe deficiency or the presence or absence of anaemia, or both, might account for these conflicting 
results, it is difficult to draw any firm conclusions until more is known about the way in which $\mathrm{Fe}$ may be involved in lymphocyte production, maturation and recirculation.

The events occurring when lymphocytes respond to an antigen are complex, consisting first of an activation stage involving interaction with antigen-presenting cells and soluble factors such as interleukins, followed by proliferation and effector activities such as antibody and lymphokine production, or cytotoxic activity. The activation stage appears to be unaffected by Fe deficiency. Kuvibidila et al. (198I) showed that sensitization to dinitrofluorobenzene was unaffected in Fe-deficient anaemic mice even though the inflammatory response was reduced, while Cummins et al. (1978) used lymphocyte transfer experiments to show that sensitization to Nippostrongylus brasiliensis was unaffected in Fe-deficient rats. In contrast, there is considerable evidence to suggest that the proliferation stage is critically affected by Fe deficiency. Hoffbrand et al. (1976) have shown that the enzyme ribonucleotide reductase is Fe-dependent, and that DNA synthesis by lymphocytes is impaired if insufficient $\mathrm{Fe}$ is available. At the same time, it has been shown that lymphocyte proliferation in vitro requires the presence of transferrin-bound Fe (Phillips \& Azari, 1974; Dillner-Centerlind et al. 1979; Brock, I98I) and that activated lymphocytes express receptors for transferrin (Galbraith et al. 1980).

A large number of investigations in the past decade have established that proliferating cells acquire transferrin-bound $\mathrm{Fe}$ by a process of receptor-mediated endocytosis, and this extensive literature has been recently reviewed elsewhere (Brock \& Mainou-Fowler, 1983; Seligman, 1983; Brock, 1985). In the case of lymphocytes, it is now known that expression of transferrin receptors occurs only after binding of interleukin-2 to the Tac receptor (Hamilton, I982; Neckers \& Cossman, 1983), which is consistent with Fe being required for the proliferative step rather than for activation or sensitization.

Studies in the authors' laboratory (Mainou-Fowler \& Brock, 1985) have shown that lymphocytes from Fe-deficient and normal mice proliferate to an equal extent when stimulated by concanavlin $A$ in vitro, but that proliferation is reduced, for both groups, if there is an inadequate supply of transferrin-bound $\mathrm{Fe}$ in the culture medium. In particular, serum from the Fe-deficient mice was less effective at supporting proliferation than normal mouse serum, irrespective of whether the cells came from normal or Fe-deficient animals. Proliferation improved if sufficient Fe was added to the Fe-deficient serum to bring the transferrin saturation to the same level as that in normal serum. This result might seem surprising, given that lymphocytes have only a modest Fe requirement (Brock \& Rankin, 198I), and that even Fe-deficient mouse serum contained at least $0.5 \mathrm{mg} \mathrm{Fe} / 1$. However, it must be remembered that the transferrin saturation will be much lower than in normal serum, so that a relatively large amount of Fe-free (apo) transferrin will be present which, despite its lower affinity for the transferrin receptor, may interfere with binding of Fe-containing molecules. From the findings of Young et al. (1984), giving the affinity of the different forms of transferrin (apo, monoferric and 
diferric) for the transferrin receptor, and that of Williams et al. (1978) for the relative proportions of each transferrin species present at different saturations, the theoretical proportions of each species binding to the cell receptors can be calculated. At $30 \%$ saturation, $37 \%$ of the receptors will be occupied by diferric transferrin, $55 \%$ by monoferric transferrin and $8 \%$ by apotransferrin, but at $10 \%$ saturation the corresponding values are $28,4 \mathrm{I}$ and $31 \%$. Thus at $10 \%$ saturation nearly one-third of the receptors will be occupied by apotransferrin, which will significantly reduce the rate at which the cells acquire $\mathrm{Fe}$, whereas at $30 \%$ saturation the proportion drops to less than one-tenth. Since the total physiological transferrin concentration is almost certainly high enough to saturate all receptors effectively, it is evident that $\mathrm{Fe}$ delivery to the cells in vivo will be affected more by transferrin saturation than by the total amount of $\mathrm{Fe}$ available. Although these are theoretical calculations, they do provide a basis for explaining reduced lymphocyte proliferation and cell-mediated immune responses observed in clinical and experimental studies. Moreover, it may be possible to reconcile some of the contradictory findings regarding the responses of lymphocytes from patients with Fe deficiency. In three of the studies which reported normal proliferation responses (Gross et al. 1975; Van Heerden et al. 1981; Krantman et al. 1982) and in which concomitant infection or protein malnutrition were excluded, cells were cultured in medium containing normal human serum rather than serum from the Fe-deficient patients.

There is little information as to whether effector functions of lymphocytes are affected by $\mathrm{Fe}$ deficiency. Production of migration inhibition factor (MIF) was found by Joynson et al. (1972) to be reduced in subjects with Fe deficiency, and the limited evidence for reduced immunoglobulin production might also be taken as evidence of impaired effector functions. However, it is not clear whether these effects were due to an intrinsic loss of effector function by the transformed cells, or whether they simply reflected a lower number of active cells due to decreased proliferation. In the authors' laboratory a recent study (Mainou-Fowler \& Brock, 1985) showed that total protein synthesis by transformed lymphocytes from Fe-deficient mice, cultured in medium containing autologous serum, was normal if allowance was made for the reduced number of transformed cells. While this does not rule out the possibility that production of certain specific proteins might be impaired it does suggest that further investigation is needed to distinguish between impaired lymphokine or immunoglobulin production and impaired proliferation.

In conclusion, it seems likely that Fe deficiency can affect lymphocyte function by preventing the activated cells from proliferating at an optimal rate. The electron-microscopy studies referred to earlier suggest that Fe deficiency may, if prolonged, also produce intrinsic defects in lymphocytes, although the effect of such defects on function remains to be established. The fact that cell-mediated responses tend to be more affected than antibody production may indicate that the proliferation step is of more critical importance in cell-mediated than humoral immunity. A recent report showing that secretion of immunoglobulin by B-cells 
does not necessarily require previous expression of transferrin receptors or proliferation (Neckers et al. 1984 ) supports this suggestion.

\section{Fe requisites of phagocytic cells}

Since neither neutrophils nor mononuclear phagocytes proliferate to any extent once they leave the bone marrow any impairment of their function associated with Fe deficiency is likely to be due to either an intrinsic defect in enzymic or other activities, or to depressed responses to chemotactic or macrophage-activating factors. The limited evidence available suggests that neutrophils from Fe-deficient subjects respond normally to chemotactic factors (MacDougall et al. 1975; Van Heerden $e$ t al. $\mathrm{Ig8} \mathrm{I}$ ) but it is not known whether Fe can influence macrophage activation.

Decreased bactericidal activity of neutrophils seems to be due primarily to defects in intracellular killing mechanisms, as ingestion was found to be normal in those studies which employed a method allowing the two stages to be distinguished (Kulapongs et al. 1974; Chandra, 1975; Van Heerden et al. 198r). Defects in intracellular killing may be related to reduced production of reactive oxygen compounds such as superoxide, as shown by reduced NBT reduction (Chandra, 1975; MacDougall et al. 1975; Celada et al. 1979). However, Prasad (1979) found that neutrophils from Fe-deficient patients had a normal capacity to produce hydrogen peroxide, but that peroxidase ( $E C$ I.I I.1.7)-mediated iodination of $E$. coli was reduced, and Yetgin et al. (r979) found that NBT reduction was normal in neutrophils from Fe-deficient children even though bactericidal activity was impaired.

The role of $\mathrm{Fe}$ in $\mathrm{O}_{2}$ metabolism in phagocytic cells is still unclear. On the one hand, $\mathrm{Fe}$ is present in cytochrome $b_{539}$ which is required for the production of superoxide (Segal \& Jones, 1978). Fe deficiency could impair synthesis of this cytochrome and thus explain the reduced NBT reduction and iodination capacities mentioned previously. On the other hand, certain forms of $\mathrm{Fe}$ can catalyse the reaction of superoxide with $\mathrm{H}_{2} \mathrm{O}_{2}$ to form the short-lived but highly reactive hydroxyl radical (Baldwin et al. 1984 ; Graf et al. 1984 ), which many believe to be the most toxic of the reactive $\mathrm{O}_{2}$ species. In theory, Fe deficiency could therefore either impair superoxide and $\mathrm{H}_{2} \mathrm{O}_{2}$ production or decrease their rate of breakdown to hydroxyl radicals. Studies of the effect of $\mathrm{Fe}$ on the function of neutrophils from normal and Fe-deficient subjects may help to improve our knowledge of how $\mathrm{O}_{2}$ metabolism is affected.

Virtually all the studies on phagocyte function in Fe deficiency have dealt with neutrophils, or uncharacterized cell populations, and almost nothing is known about the effect on macrophages. Addition of $\mathrm{Fe}$ did not affect $\mathrm{H}_{2} \mathrm{O}_{2}$ production by cultured mouse macrophages (Thompson et al. 1986), although the haemoglobin content of erythrocytes reduced both $\mathrm{H}_{2} \mathrm{O}_{2}$ production (L. S. Stewart and J. H. Brock, unpublished results) and tumouricidal activity (Weinberg \& Hibbs, 1977). However, none of these observations related to cells from $\mathrm{Fe}$-deficient animals. 


\section{Conclusions}

The present review has attempted to assess critically the evidence for involvement of $\mathrm{Fe}$ in immune mechanisms and, in particular, the evidence for altered immune responses associated with Fe deficiency. It is clear that the most urgent need is for further investigations aimed at elucidating the role of $\mathrm{Fe}$ in the cellular and molecular events occurring during immune responses. Such information may help to explain the frequently conflicting results obtained in studies with patients, and allow the clinician to decide whether Fe deficiency or other factors are more likely to be the cause of reduced immune responsiveness in malnourished patients.

\section{REFERENCES}

Antonini, E., Orsi, N. \& Valenti, P. (1977). Giomale di Malattie, Infettive e Parassitarie (Milano) 29, $481-489$.

Bagchi, K., Mohanram, M. \& Reddy, V. (1980). British Medical fournal 280, 1249-1251.

Baggs, R. B. \& Miller, S. A. (1973). Fournal of Nutrition 103, 1554-1560.

Baggs, R. B. \& Miller, S. A. (1974). Fournal of Infectious Diseases 130, 409-411.

Baldwin, D. A., Jenny, E. R. \& Aisen, P. (1984). Fourmal of Biological Chemistry 259, 13391-13394.

Bishop, J. G., Schanbacher, F. L., Ferguson, L. C. \& Smith, K. C. (1976). Infection and Immunity I4, $911-918$.

Brock, J. H. (1980). Archives of Disease in Childhood 55, 417-421.

Brock, J. H. (1981). Immunology 43, 387-392.

Brock, J. H. (1985). In Metalloproteins, vol. 2, pp. 183-262 [P. M. Harrison, editor]. London: Macmillan.

Brock, J. H. \& Mainou-Fowler, T. (1983). Immunology Today 4, 347-351.

Brock, J. H. \& Ng, J. (1983). FEMS Microbiology Letters 20, 439-442.

Brock, J. H., Pickering, M. G., McDowall, M. C. \& Deacon, A. G. (1983). Infection and Immunity 40, 453-459.

Brock, J. H. \& Rankin, M. C. (1981). Immunology 43, 393-398.

Bullen, J. J., Rogers, H. J. \& Leigh, L. (1972). British Medical Yournal 1, 69-75.

Celada, A., Herreros, V., Pugin, P. \& Rudolf, M. (1979). British Foumal of Haematology 43, 457-463.

Chandra, R. K. (1975). Fournal of Pediatrics 86, 899-902.

Corda, R., Biddau, P., Corrias, A. \& Puxeddu, E. (I983). International Fournal of Tissue Reactions 5, 11 7-123.

Cummins, A. G., Duncombe, V. M., Bolin, T. D., Davis, A. E. \& Kelly, J. D. (1978). Gut I9, $823-826$.

Dillner-Centerlind, M.-L., Hammerström, S. \& Perlmann, P. (1979). European fournal of Immunology $9,942-948$.

Duncombe, V. M., Bolin, T. D., Davis, A. \& Kelly, J. D. (1979). American Fournal of Clinical Nutrition 32, $553-55^{8}$.

Duncombe, V. M., Bolin, T. D., Davis, M., Fagan, M. R. \& Davis, A. E. (1980). Australian foumal of Experimental Biology and Medical Science 58, 19-26.

Elin, R. J. \& Wolff, S. M. (1974). Fournal of Immunology 112, 737-745.

Finkelstein, R. A., Sciortino, C. V. \& McIntosh, M. A. (1983). Reviews of Infectious Diseases 5, Suppl. 4, S759-S777. $^{2}$

Fletcher, J., Mather, J., Lewis, M. J. \& Whiting, G. (1975). Journal of Infectious Diseases I31, 44-50.

Galbraith, G. M. P., Goust, J. M., Mercurio, S. M. \& Galbraith, R. M. (1980). Clinical Immunology and Immunopathology 16, 387-395. 
Graf, E., Mahoney, J. R., Bryant, R. G. \& Eaton, J. W. (1984). Fournal of Biological Chemistry 259, 3620-3624.

Greenberg, E. R. \& Cline, B. L. (1979). American Journal of Tropical Medicine and Hygiene 28, 770-772.

Gross, R. L., Reid, J. V. O., Newberne, P. M., Burgess, B., Marston, R. \& Hift, W. (1975). American fournal of Clinical Nutrition 28, 225-232.

Gupta, K. K., Dhatt, P. S. \& Singh, H. (1982). Indian Fournal of Pediatrics 49, 507-510.

Hamilton, T. A. (1982). Fournal of Cellular Physiology $1 \times 3,40-46$.

Higgs, J. M. \& Wells, R. S. (1972). British Fournal of Dermatology 86, Suppl. 8, 88-102.

Hoffbrand, A. V. (1980). In Iron in Biochemistry and Medicine II, pp. 499-527 [A. Jacobs and M. Worwood, editors]. London: Academic Press.

Hoffbrand, A. V., Ganeshaguru, K., Hooton, J. W. L. \& Tattersall, M. H. N. (1976). British fournal of Haematology 33, 517-526.

Jacobs, A. (1977). In Iron Metabolism, Ciba Foundation Symposium no. 51, pp. 91-106. Amsterdam: Elsevier.

Jacobs, A. \& Joynson, D. H. M. (1974). Lancet ii, 844 .

Jarvis, J. H. \& Jacobs, A. (1972). Journal of Clinical Pathology 27, 973-979.

Jimènez, A., Sànchez, A., Vàzquez, R. \& Olmos, J. M. (1982). Morfologia Normal y Patológica 6B, $279-287$.

Joynson, D. H. M., Jacobs, A., Walker, D. M. \& Dolby, A. E. (1972). Lancet ii, 1058-1059.

Krantman, H. J., Young, S. R., Ank, B. J., O'Donnell, C. M., Rachelefsky, G. S. \& Stiehm, E. R. (1982). American Journal of Diseases of Children 136, 840-844.

Kulapongs, P., Vithayasai, V., Suskind, R. \& Olson, R. E. (1974). Lancet ii, 689-6gr.

Kuvibidila, S. R., Baliga, B. S. \& Suskind, R. M. (Ig81). American foumal of Clinical Nutrition $34,2635-2640$.

Kuvibidila, S. R., Baliga, B. S. \& Suskind, R. M. (1982). Nutrition Reports International 26, $86 \mathrm{I}-87 \mathrm{r}$.

Kuvibidila, S. R., Baliga, B. S. \& Suskind, R. M. (1983a). American Yournal of Clinical Nutrition $3^{8}, 23^{8-244 .}$

Kuvibidila, S. R., Nauss, K. M., Baliga, B. S. \& Suskind, R. M. (1983b). American fournal of Clinical Nutrition 37, I5-25.

Kuvibidila, S. R., Nauss, K. M., Baliga, B. S. \& Suskind, R. M. (1983c). American Fournal of Clinical Nutrition 37, 557-565.

Lalonde, R. G. \& Holbein, B. E. (1984). Fournal of Laboratory and Clinical Medicine 73, $470-476$.

MacDougall, L. G., Anderson, R., McNab, G. M. \& Katz, J. (1975). Fournal of Pediatrics 86, $833-843$.

MacDougall, L. G. \& Jacobs, M. R. (1978). South African Medical Fournal 53, 405-407.

Mainou-Fowler, T. \& Brock, J. H. (1985). Immunology 54, 325-332.

Mickelsen, P. A., Blackman, E. \& Sparling, P. F. (1982). Infection and Immunity 35, 915-920.

Moreau, M. L., Duval-Iflah, Y., Muller, M. C., Raibaud, P., Vial, M., Gabilan, J. C. \& Daniel, N. (1983). Annales de Microbiologie (Institut Pasteur) 134B, 429-441.

Nalder, B. N., Mahoney, A. W., Ramakrishnan, R. \& Hendricks, D. G. (1972). Journal of Nutrition 102, 535-542.

Neckers, L. M. \& Cossman, J. (1983). Proceedings of the National Academy of Sciences, USA 80, $3494-3498$.

Neckers, L. M., Yenokida, G. \& James, S. P. (1984). Fournal of Immunology 133, 2437-2441.

Neilands, J. B. (198I). Annual Reviews of Biochemistry 50, 715-73I.

Phillips, J. L. \& Azari, P. (1974). Cellular Immunology 15, 94-99.

Pollack, S., Vanderhoff, G. \& Lasky, F. (1977). Biochimica et Biophysica Acta 497, 481-487.

Prasad, J. S. (1979). American fournal of Clinical Nutrition 32, 550-552.

Puschmann, M. \& Ganzoni, A. M. (1977). Infection and Immunity 17, 663-664.

Reiter, B., Brock, J. H. \& Steel, E. D. (1975). Immunology 28, 83-95.

Rothenbacher, H. \& Sherman, A. R. (1980). Fournal of Nutrition 1 10, 1648-1654.

Sawitsky, B., Kanter, R. \& Sawitsky, A. (1976). American Fournal of Medical Science 272, $153-160$.

Segal, A. W. \& Jones, O. T. G. (1978). Nature 276, 515-517.

Seligman, P. A. (1983). Progress in Hematology $13,131-147$. 
Soyano, A., Candellet, D. \& Layrisse, M. (1982). International Archives of Allergy and Applied Immunology 69, 353-357.

Srikantia, S. G., Prasad, J. S., Bhaskaram, C. \& Krishnamachari, K. A. V. R. (1976). Lancet i, $1307-1309$.

Thompson, H. L., Stevenson, J. \& Brock, J. H. (Ig86). FEBS Letters (In the Press).

Van Heerden, C., Oosthuizen, R., Van Wyk, H., Prinsloo, P. \&c Anderson, R. (1981). South African Medical Yournal 59, I I I-I 13.

Weinberg, E. D. (1984). Physiological Reviews 64, 65-102.

Weinberg, J. B. \& Hibbs, J. R. (1977). Nature 269, 245-247.

Williams, J., Evans, R. W. \& Moreton, K. (1978). Biochemical fournal 173, 535-542.

Yetgin, S., Altay, C., Ciliv, G. \& Laleli, Y. (1979). Acta Haematologica 61, 10-14.

Young, S. P., Bomford, A. \& Williams, R. (1984). Biochemical fournal 219, 505-510. 